Selcuk Journal of Agriculture and Food Sciences

$\underline{\text { http://sjafs.selcuk.edu.tr/sjafs/index }}$

Research Article
SJAFS

(2021) 35(1), 56-64

e-ISSN: $2458-8377$

DOI:10.15316/SJAFS.2020.229

\title{
Prediction of Draft Force and Disturbed Soil Area of a Chisel Tine in Soil Bin Conditions Using Draft Force and Its Comparison with Regression Model
}

\author{
Kazım Çarman ${ }^{1}$, (D) Tamer Marakoğlü,*, (D) Alper Taner ${ }^{2}$, (D) Ergün Çııtı1 ${ }^{1}$
}

${ }^{1}$ Selçuk University, Faculty of Agriculture, Department of Agricultural Machinery and Technologies Engineering, Konya, Turkey

${ }^{2}$ Ondokuz Mayis University, Faculty of Agriculture, Department of Agricultural Machinery and Technologies Engineering, Samsun, Turkey

\begin{tabular}{|c|c|}
\hline ARTICLE INFO & ABSTRACT \\
\hline $\begin{array}{l}\text { Article history: } \\
\text { Received date: } 19.02 .2021 \\
\text { Accepted date: } 02.04 .2021\end{array}$ & $\begin{array}{l}\text { One of our most valuable natural resources is soil. Sustainable agricultural pro- } \\
\text { duction is achieved with proper soil management. Tillage is considered to be one } \\
\text { of the largest operations, as the most energy need in agricultural production oc- } \\
\text { curs in tillage. }\end{array}$ \\
\hline $\begin{array}{l}\text { Edited by: } \\
\text { Osman ÖZBEK; Selcuk University, } \\
\text { Turkey }\end{array}$ & $\begin{array}{l}\text { The main purpose of this study is to investigate the effects of chisel tine on draft } \\
\text { force and disturbed soil area and estimate them using artificial neural networks } \\
\text { (ANN) and multiple linear regression equations (MLR). The experiments were } \\
\text { carried out in a closed soil bin filled with clay loam soil at an average moisture }\end{array}$ \\
\hline $\begin{array}{l}\text { Keywords: } \\
\text { Artificial Neural Networks } \\
\text { Draft Force } \\
\text { Disturbed Soil Area } \\
\text { Chisel Tine }\end{array}$ & $\begin{array}{l}\text { content of } 13.2 \% \text { (on dry basis). The draft force and disturbed soil area were } \\
\text { evaluated as affected by the share width at two levels }(60 \text { and } 120 \mathrm{~mm}) \text {, forward } \\
\text { speed at four levels }\left(0.7,1,1.25 \text { and } 1.5 \mathrm{~ms}^{-1}\right) \text { and working depth at four levels } \\
(160,200,240 \text { and } 280 \mathrm{~mm}) \text { at three replications. The draft force varied from } \\
0.5 \text { to } 1.42 \mathrm{kN} \text {, depending on the controlled variables, while the disturbed soil } \\
\text { area varied from } 260 \text { to } 865 \mathrm{~cm}^{2} \text {. Test results show that share width, forward } \\
\text { speed and working depth were significant on the draft force and disturbed soil } \\
\text { area. Input variables of the ANN models were considered share width, forward } \\
\text { speed and working depth. In prediction of required draft force and disturbed soil } \\
\text { area respectively, on account of statistical performance criteria, the best ANN } \\
\text { model with coefficient of determination of } 0.999 \text { and } 0.998 \text {, root mean square } \\
\text { error of } 0.010 \text { and } 0.016 \text { and mean relative percentage error of } 0.960 \text { and } 1.673 \\
\text { was better performed than the MLR model. }\end{array}$ \\
\hline
\end{tabular}

\section{Introduction}

Artificial intelligence systems are widely accepted as a technology providing an alternative method to solve complex and ill-defined problems. Artificial neural network (ANN) is a technique with a flexible mathematical structure, which is capable of identifying a complex nonlinear relationship between the input and output data (Çarman et. al., 2016)

The tillage system chosen to produce an agricultural product has a significant impact on soil erosion, water quality and profitability. Of course, profitability is determined from product yield and costs. However, it is useful to include evaluations of not only short term yield but also long term effects on soil loss and productivity. Choosing a tillage system is therefore an important management decision (Fawcett and Towery, 2005; Anderson, 2009; Simmons and Nafziger, 2010).
Conservation tillage is generally defined as any crop production system that provides at least $30 \%(30-60 \mathrm{~cm}$ high) on upright stubble after planting and at least 50$60 \%$ residual cover on prostrate stubble after planting to reduce soil erosion from water. At least $110 \mathrm{gm}^{-2}$ of flat, small grain residue on the soil surface during critical erosion period to reduce soil erosion due to wind (Fawcett and Towery, 2005; Anderson, 2009; Simmons and Nafziger, 2010; Scott et al., 2010).

The chisel plow is considered the primary soil tillage tool as it is mainly used for initial tillage operations. It is widely used by Middle Anatolia farmers to reduce soil strength and to cover plant materials in recent years.

The most important part of chisel plow is the leg and they are manufactured in different sizes and shapes. Winged chisel plows, which have become widespread in recent years, have become more prominent than conventional chisel plows due to their positive effects on the

\footnotetext{
* Corresponding author email: marakoglu@selcuk.edu.tr
} 
soil (Godwin and O’Dogherty, 2007; Kees, 2008; Salar et al., 2013). Nowadays, wings at certain horizontal angles have been added to both sides of the winged chart leg. These wings cut the soil horizontally from below. One of the major drawbacks of deep work chisel plows is their high drawbar force requirements. Therefore, they cause a significant energy consumption. However, specific energy consumption per unit deformation area decreases due to the large deformation area they cause. The draft force of the machine varies depending on the soil properties, the working speed of the tool and the geometric structure of the tool (Boydas, 2004; Zadeh, 2006; Armin, 2014; Neisy, 2014).

A research has been reported by Abbaspour-Gilandeh et al., (2008) in an attempt to develop the prediction model of draft force and required energy for tillage operation. In this study, artificial neural network model was used. Input parameters such as working speed, tillage depth and different soil parameters (cone index, moisture content, clay and sand percentage) were used. In regard to the high accurate prediction (98.8\%) and high accurate simulation (97.6\%) the application of Lavenberg-Marquardt algorithm with 2 middle layers including 12 neurons on its first layer and 10 neurons on its second layer was distinguished as the most appropriate algorithm in comparison with other ones. Artificial neural networks were used to predict the draft force of a rigid tine chisel cultivator by Abbaspour-Gilandeh et al. (2020). They found that the average simulation accuracy and correlation coefficient for estimating the draft force of a chisel cultivator were $99.83 \%$ and 0.9445 , respectively. The linear regression model had a much lower accuracy and correlation coefficient for predicting the draft force compared to artificial neural networks.

Karmakar (2005) reported that artificial neural networks have been used as possible approach to solve problems in the area of soil tool interaction. It is noteworthy that there is a growing interest in modelling draft and energy requirements of tillage implements using ANN due to complexity and unavailable analytical models for all tillage implements. Al-Janobi et al. (2001) used a Multilayer Perceptron with error backpropagation learning algorithm to construct neural network model to predict the specific draft $\left(\mathrm{kN} \mathrm{m}^{-1}\right)$ of four different tillage implements from the field data. The proposed neural network model, by testing, indicated that there is a small variation of measured and predicted data with linear correlation coefficient equals to 0.987 and mean squared error between experimental and predicted specific draft equals to 0.1445 .

Rahman et al. (2011) developed an artificial neural network model to estimate the energy needs of a soil cultivation tool from laboratory data. The artificial neural network model was trained and tested with soil moisture content, plowing depths and forward operating speeds as input parameters. The measured energy requirement for a soil tillage tool in silty clay loam was used as the output parameter. Their results showed that the measured and predicted variation in energy requirement was small.

When all these studies were evaluated, parametric studies were not conducted to show the tendency and effect of individual variables on the chisel tine's disturbed soil area and draft force in the soil bin. Occasionally, farm mechanization manager wants to know the magnitude of disturbed soil area and draft force of a tillage implement at levels of separate forward speed and working depth. In these cases, numerous experiments are needed to get draft and deformation area data and the cost is very high. So, simulation technique to generate draft and soil deformation area data using artificial neural networks is useful in this case, because the results obtained depend on data performing in the soil bin.

In general, the objectives of this research can be stated as follows:

1. To evaluate the effect of tine width, forward speed and working depth on soil disturbance area and draft force requirements of chisel tine.

2. Investigating the ability of artificial neural network and multiple linear regression approaches for predicting the draft force and disturbed soil area by chisel tines.

3. Comparison of the accuracy with statistical parameters and soil bin data of draft force and disturbed soil area predictions using artificial neural network and multiple linear regression model

\section{Materials and Methods}

This study was conducted in a soil bin in Selcuk University Faculty of Agriculture, Department of Agricultural Machinery and Technologies Engineering. The soil bin used in this study is $20 \mathrm{~m}$ long, $2.25 \mathrm{~m}$ wide and $1 \mathrm{~m}$ deep. Soil bin facilities built for testing agricultural equipment were described in detail by Marakoğlu et al. (2013). Test machine moves on rails by means of chaingear driven with electric engine. The chisel tine has been connected as without stage adjustable on vertical planes to front of test machine. All units of the soil bin are manufactured to be demountable. This situation provides convenience for the repair of any part of the system in case of deformation or failure.

The chisel tine used in the study is fixed and the chisel share have been changed. The construction details of chisel tine are shown in Figure 1. The Chisel share has a rake angle of $34^{\circ}$, a concavity depth of $21 \mathrm{~mm}$ and a concavity radius of $546 \mathrm{~mm}$. The test chisel tine variables included chisel share widths (W) 60 and $120 \mathrm{~mm}$, working depths (D) 160, 200, 240 and $280 \mathrm{~mm}$, and forward speeds (V) 0.7, 1.0, 1.25 and $1.5 \mathrm{~m} \mathrm{~s}^{-}-1$. Chisel tine were tested in a soil bin using fully randomized factorial $(2 \times 4 \times 4)$ experiments (triple replicates). 


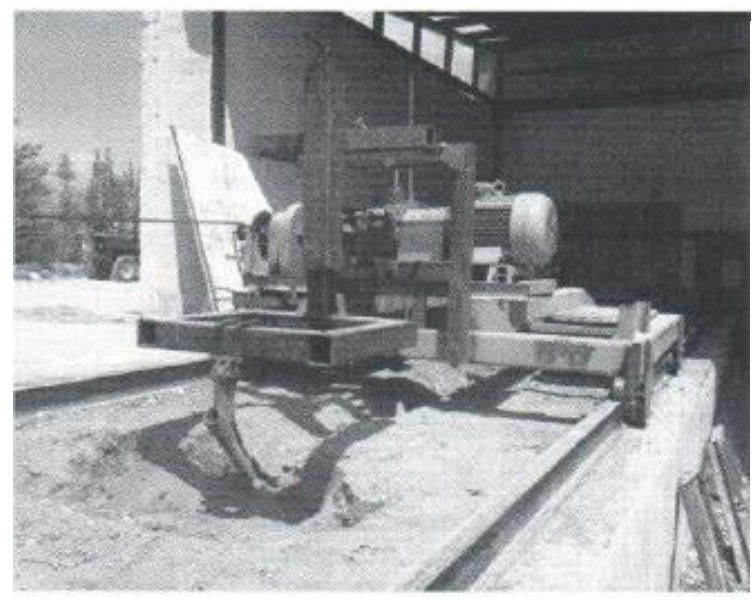

Figure 1

The soil bin and chisel tine used in trials.

The soil bin was filled with a $0.5 \mathrm{~m}$ thick layer of clay loam. The soil has a texture of clay-loam (sand: $38 \%$, loam: $27 \%$, clay: $35 \%$ ) with a moisture content of $13.5 \%$, a shear stress of $1.50 \mathrm{Ncm}^{-2}$ a bulk density of $1.41 \mathrm{Mgm}^{-3}$ and a penetration resistance of $1650 \mathrm{kPa}$. The soil surface was leveled with smoothing shovel that had been connected to rear of test machine before each trial, and then the soil compacted by heavy flat roller loaded of $0.9 \mathrm{daN}$ to unit area $\left(\mathrm{cm}^{2}\right)$.

A speed measuring system has been developed to measure the forward speed. This system consists of a stopwatch and two speed sensors. The distance between the two sensors is $15 \mathrm{~m}$. The forward speed has been determined by considering the distance and time between the two sensors.

To determine the draft requirement of the chisel tine, a load cell was used to measure the draft force during the operation of a chain drive for the front and rear motions of the testing machine. In measurements, a horizontal load cell connecting the analog amplifier and digital data logger was used. In force measurements, 5 values were read per second and these results were averaged by data logger. Obtained force data was recorded as gross traction forces (GF). In addition, the rolling resistance force (RF) of the test machine at idle (no load) operation was recorded. Subsequently, required draft force (DF) of the chisel tine was computationally obtained by means of the following equation.

\section{$\mathrm{DF}=\mathrm{GF}-\mathrm{RF}$}

Where, $\mathrm{DF}$ is draft force $(\mathrm{kN})$; GF is gross traction force $(\mathrm{kN})$, and $\mathrm{RF}$ is rolling resistance force $(\mathrm{kN})$.

In order to determine the disturbed soil area, a sheet plate of 700x400x5 mm was placed as a perpendicular to the direction of forward and in a vertical plane on the soil treated. The soil on the front of the sheet metal has been evacuated and the sheet metal has been removed. The untreated area in front of the opened profile and the disturbed limit were determined by applying lime with a brush. Three copies of the disturbed soil section profile were photographed after each application. Then the resulting total area of disturbed soil were calculated by plotting the measured coordinates of the cross sections

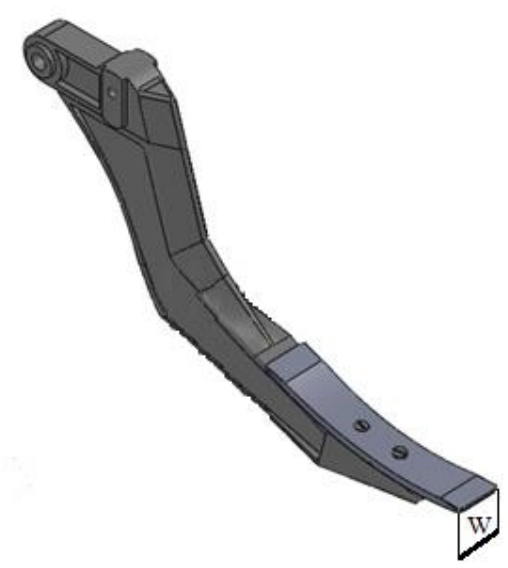

areas using the Fiji image computer package (Topakc1, 2004; Marakoğlu et al, 2013).

The ANNs designed in this study were multilayer back-propagation multilayer networks. Many studies performed for prediction works have used the scaled conjugate gradient, gradient descent with momentum, and Levenberg-Marquardt algorithms (Suzuki 2013). Multilayer networks are beneficial for prediction applications if they have enough neurons in the hidden layer. The multilayer networks are susceptible to the number of neurons in the hidden layer(s). A high number of neurons causes overfitting and the network may lose its ability to generalize, and a low number of neurons can cause mismatch. In network design, minimizing the number of neurons in a hidden layer without affecting the network performance is one of the important criteria. The most important factor in the design of ANNs is the selection of data used as the training data and testing data. The input parameters were share width, forward speed of test machine and working depth. The draft force and disturbed soil area of the chisel tine were the output parameters of the designed network.

To train the designed network and test the network, the collected data were divided into two separate files: 24 of the total data were used for network training and 8 for network testing.

While establishing the ANN model, all the data were normalized between 0 and 1 (Purushothaman and Srinivasa, 1994). For normalization, the following equation was used:

$$
y_{\text {nor }}=\frac{y-y_{\text {min }}}{y_{\max }-y_{\min }},
$$

To obtain real values from the normalized values, "y" value was calculated using the same formula.

In order to evaluate and compare the performance of ANNs with the multiple linear regression model, the regression models were developed to predict the draft force (DF) and disturbed soil area (DSA) of the chisel tine. SPSS 19 software was used to obtain the multiple linear regression model. The parameters included in the models were the chisel share width $(\mathrm{W})$, forward speed 
(V) and working depth (D) as independent variables. The multiple linear regression equation obtained from the experimental data were given below;

$$
\begin{aligned}
& \mathrm{DF}=-0.0693+0.2862 \mathrm{~W}+0.0475 \mathrm{~V}+0.1655 \mathrm{D}, \\
& \mathrm{DSA}=-185.083+306.125 \mathrm{~W}+28.742 \mathrm{~V}+74.566 \mathrm{D},
\end{aligned}
$$

The commonly used RMSE, $\mathrm{R}^{2}$ and values, which are accepted as the basic accuracy criterion to determine the performance of the results and based on the concept of mean error, were calculated using the following formulas (Bağırkan, 1993; Bechtler et al., 2001).

$$
\begin{aligned}
& R M S E=\left(\frac{1}{n} \sum_{i=1}^{n}\left(x_{1 i}-x_{i}\right)^{2}\right)^{1 / 2}, \\
& R^{2}=1-\left(\sum_{i=1}^{n}\left(x_{1 i}-x_{i}\right)^{2}\right) /\left(\sum_{i=1}^{n}\left(x_{1 i}\right)^{2}\right), \\
& \varepsilon=\frac{100}{n} \sum_{i=1}^{n}\left|\frac{\left(x_{i}-x_{1 i}\right)}{x_{1 i}}\right|
\end{aligned}
$$

Here, RMSE, Root Mean Square Error, $\mathrm{R}^{2}$, coefficient of determination, $\varepsilon$, relative error, $n$, number of data, $x$, measured value and, $x 1$, predicted value.

\section{Results and Discussion}

The draft force required of chisel tine increased with increasing share width, forward velocity and working depth (Figure 2). The draft force varied from 0.52 to $1.42 \mathrm{kN}$. The effect on draft force of share width, forward velocity and working depth were significant $(\mathrm{p}<$ 0.01 ). An increased of $100 \%$ at share width resulted in a draft force increase of $38 \%$. Approximately, an increased of $114 \%$ at forward velocity resulted in a draft force increase of $17 \%$ while an increased of $75 \%$ at working depth caused a $49 \%$ increased of the draft force. The greatest value in draft force was obtained at a share width of $120 \mathrm{~mm}$, working depth of $280 \mathrm{~mm}$ and forward velocity of $1.5 \mathrm{~m} \mathrm{~s}^{-1}$. Askari and Abbaspour-Gilandeh (2019) found that the highest values of draft force are related to the winged subsoiler in depth of $50 \mathrm{~cm}$ and speed of $3.5 \mathrm{~km} / \mathrm{h}$ as $30.9 \mathrm{kN}$ and the lowest one are related to the bent leg at the depth of $30 \mathrm{~cm}$ and speed of $1.8 \mathrm{~km} / \mathrm{h}$ as $5.6 \mathrm{kN}$. The draft force was usually higher for higher working depth. Working depth was the major contributory factor on draft force as compared to forward velocity.

The draft force of the subsoil tillage tines is less affected by the forward speed but is much affected by tine type, tillage depth and wing width (Askari et al., 2017). In the study conducted by Çarman et al., (2019), they found that the working depth was more effective on the draft force of the moldboard plough. Manuwa et al., (2010) found that the draft force increased at a decreasing rate with tine width. The increase is also affected by the forward speed since higher draft force values were obtained at higher speed. Boydaş (2017) studied the effect on draft force of various wing mouth forms in chisel plough shank. Draft force was significantly affected from the wing forms. The highest draft force $(222.70 \mathrm{~N})$ obtained from the smooth mouth wing, and the lowest draft force $(183.45 \mathrm{~N})$ occurred with the narrow angle teeth wing.

Al-Suhaibani and Ghaly (2013) found that increasing the chisel plowing depth and decreasing the forward speed increased the specific draft force. Increasing the working depth from $115 \mathrm{~mm}$ to $230 \mathrm{~mm}$ (100\%) increased the specific draft force by $161-165 \%$ while increasing the forward speed from $0.75 \mathrm{~m} / \mathrm{s}$ to $2.25 \mathrm{~m} / \mathrm{s}$ (200\%) decreased the specific draft force by $52-53 \%$ for the heavy duty chisel plows.

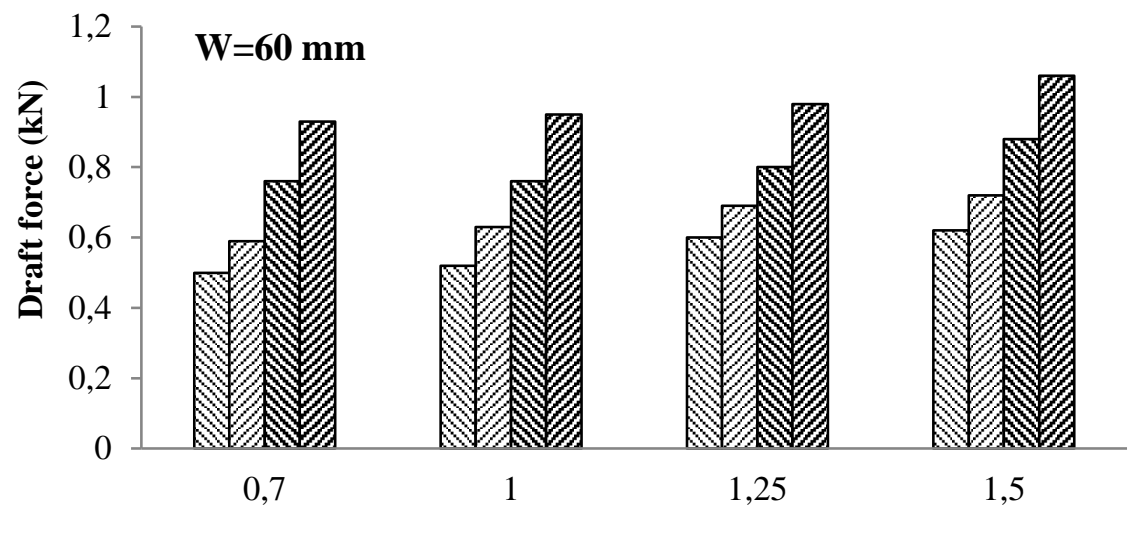




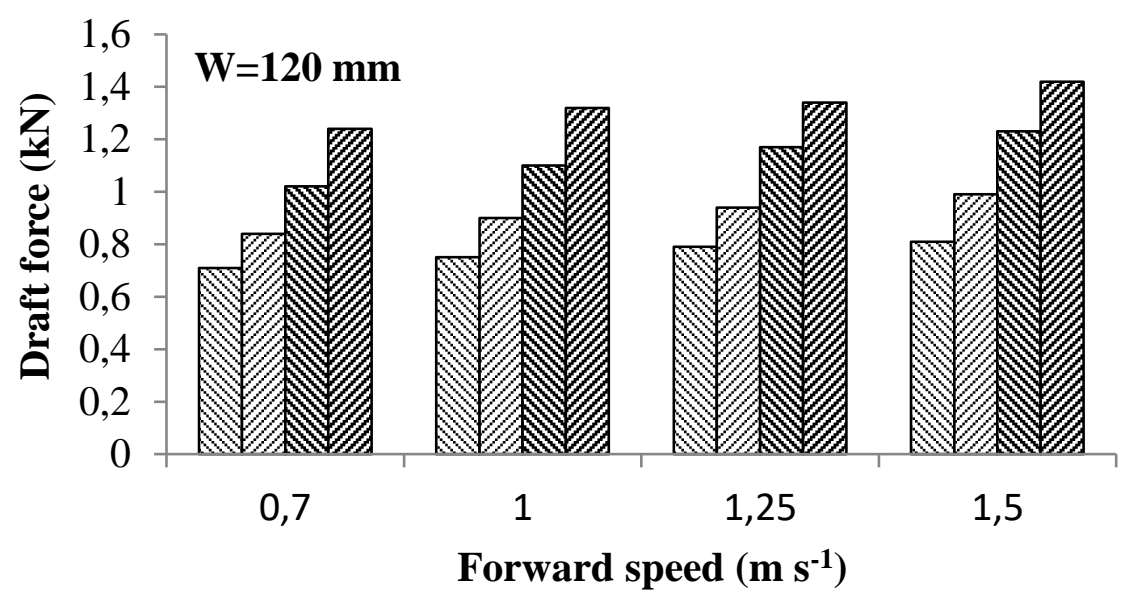

ه $160 \mathrm{~mm} \nabla 200 \mathrm{~mm} \approx 240 \mathrm{~mm} \square 280 \mathrm{~mm}$

Figure 2

The draft force requirement of chisel tine as a depending on share width, forward speed and working depth.

The disturbed soil area of chisel tine in a clay loam soil under varying operating conditions were given in Figure 3. The disturbed soil area was varied from 260 to $865 \mathrm{~cm}^{-2}$ as depending on different share width, forward speed and tillage depths. Averagely, the lowest value of disturbed soil area was obtained at share width $60 \mathrm{~mm}$, speed of $0.7 \mathrm{~m} \mathrm{~s}^{-1}$ and working depth of $160 \mathrm{~mm}$, and the highest value was obtained at share width $120 \mathrm{~mm}$, speed of $1.5 \mathrm{~m} \mathrm{~s}^{-1}$ and working depth of $280 \mathrm{~mm}$. An increased of $100 \%$ at share width resulted in a disturbed soil area increase of $80 \%$. Approximately, an increased of $114 \%$ at forward velocity resulted in a disturbed soil area increase of $17 \%$ while an increased of $75 \%$ at working depth caused a $53 \%$ increased of the disturbed soil area. The increase in tillage depth was more effective on the disturbed soil area compared to the increase in forward speed. The results obtained from the experimental data were analyzed using analysis of variance. (ANOVA). The results showed a significant difference among the disturbed soil area values for the two different share width, four different forward speed and working depth at $1 \%$ probability level.

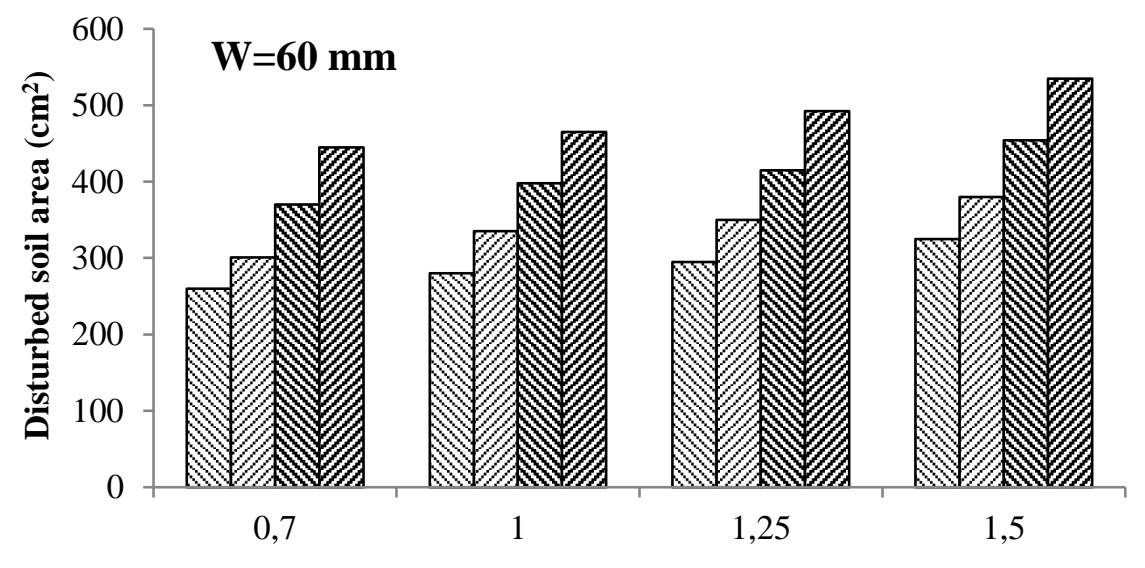




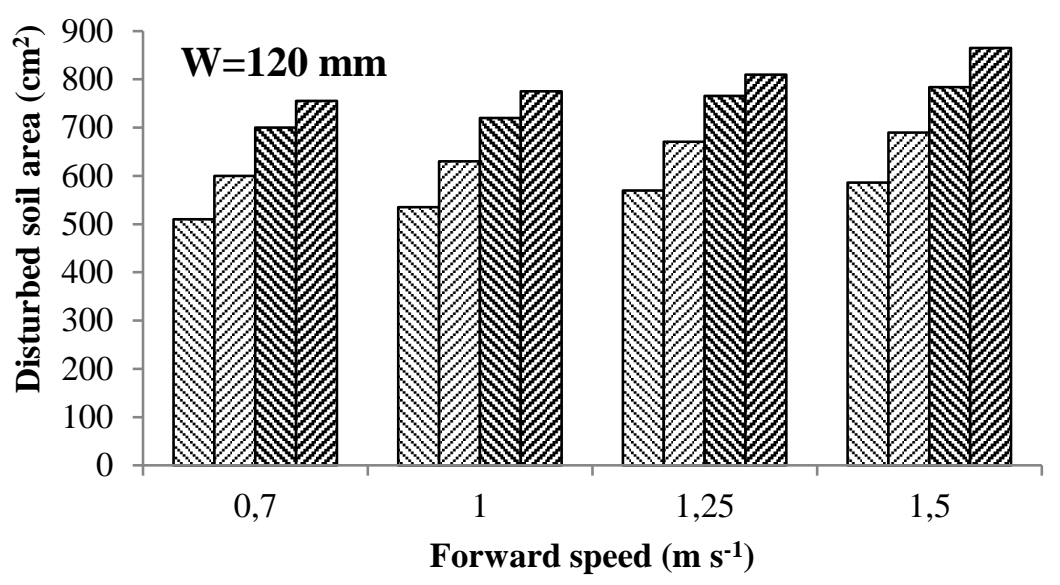

\$160 mm $\square 200 \mathrm{~mm}$ \$240 $\mathrm{mm} \quad 280 \mathrm{~mm}$

Figure 3

The disturbed soil area of chisel tine as a depending on share width, forward speed and working depth.

Topakc1 (2004) studied under the controlled conditions with chisel tine in soil bin. The experiments were carried out the different tine wing arrangements and leading tine arrangements. The disturbed soil area was varied from 893.8 to $1655.2 \mathrm{~cm}^{2}$. It can be said that the greater values obtained from our study were caused by wing arrangements and deeper operating conditions. Marakoğlu et al. (2013) found the total disturbed soil area as 939 and $639 \mathrm{~cm}^{2}$, respectively, in their study conducted with winged and simple chisel tine in soil bin.

In the ANN model, the structure of the network is 3(6-8)-2, and it was designed as 3 input layers, 2 hidden layers and 2 output layers, and the neuron numbers of hidden layers were obtained as 6-8 (Figure 4). In the structure of the created network, logsig in the first hidden layer, purelin in the second hidden layer and tansig transfer functions in the output layer are used. For the network, the lowest training error value was obtained at 96 epochs. Abbaspour-Gilandeh et al. (2008) conducted trials to develop the prediction model of draft force and required energy for tillage operation. In this study, parameters such as forward speed, tillage depth and different soil parameters were used. Artificial neural network model is used in this study. The best training algorithm was selected based on the comparison of made networks (in training and data test stages). In regard to the high accurate prediction $(98.8 \%)$ and high accurate simulation $(97.6 \%)$ the application of Lavenberg-Marquardt algorithm with 2 middle layers including 12 neurons on its first layer. 10 neurons on its second layer was distinguished as the most appropriate algorithm in comparison with other ones.

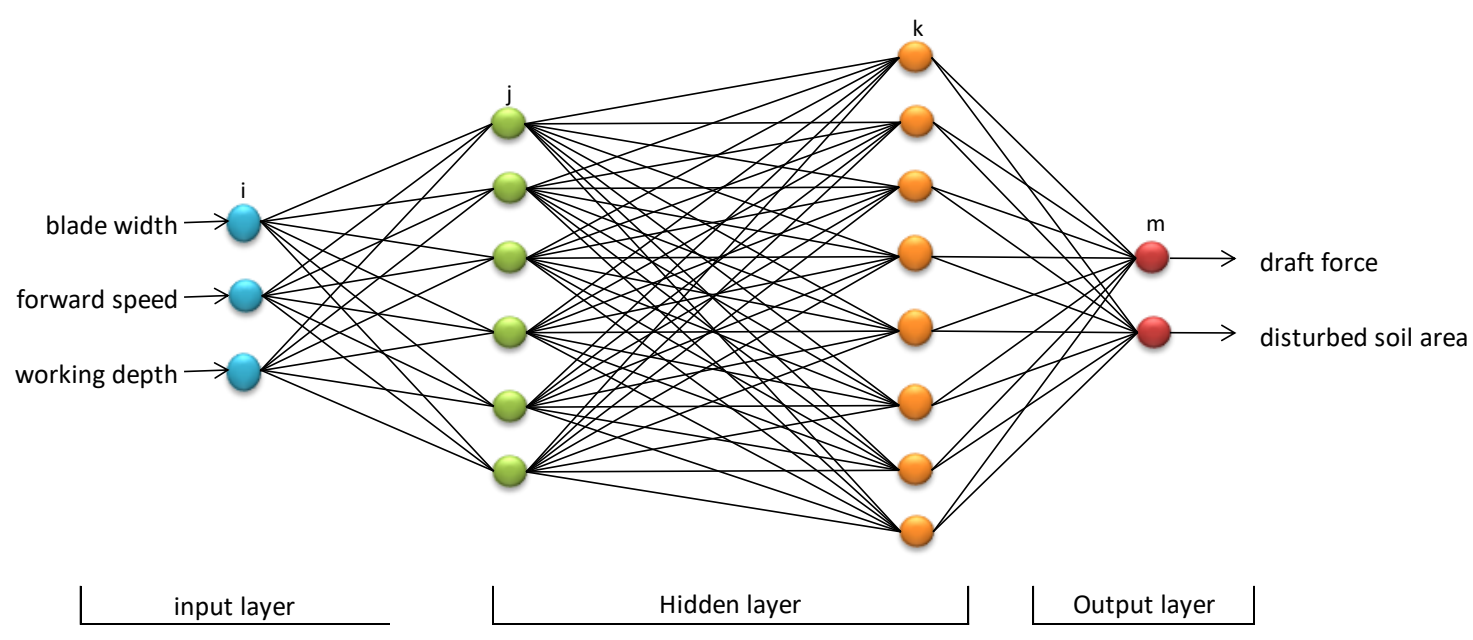

Figure 4

The network structure of the ANN model

The prediction ability of the developed models is investigated according to mathematical and statistical methods. Table 1 shows the mean values of RMSE, $\mathrm{R}^{2}$ and $\mathcal{E}$ of the ANN and regression models to predict each

of the two output parameters. For draft force, the statistical values RMSE and $\mathrm{R}^{2}$ in ANN model were found as 0.010 and 0.999 , respectively. In ANN model, the mean relative error values were found as $0.960 \%$. The statis- 
tical values RMSE and $\mathrm{R}^{2}$ in regression model were found as 0.040 , and 0.992 , respectively. In regression mo$\mathrm{del}$, the mean relative error values were found as 3.756 $\%$. Abbaspour-Gilandeh et al. (2020) compared the performance of ANNs with a linear regression model, and the data obtained from the two models were compared to estimate the draft force of the chisel cultivator. They found that the correlation coefficient and prediction accuracy for the linear regression model were $0.592 \%$ and $61 \%$, respectively, and the correlation coefficient and prediction accuracy of the ANN model were significantly lower than the prediction accuracy of $0.9445 \%$ and $89 \%$, respectively. These results are consistent with the results of our study. Draft force data for chisel plows working with different soil conditions and operational parameters were obtained with the help of simulation results using artificial neural networks by Aboukarima (2007). The coefficients of determination $\left(\mathrm{R}^{2}\right)$ of of prediction were found higher than $93 \%$.

Manuwa (2009) reported that a good relationship between draft force measurements and predicted using

Table 1

Performance of the ANN and Regression models to predict each of the two output parameters

\begin{tabular}{lccc}
\hline Models & Performance Values & Draft Force $(\mathrm{kN})$ & Disturbed Soil Area $\left(\mathrm{cm}^{2}\right)$ \\
\hline \multirow{3}{*}{ ANN } & RMSE & 0.010 & 0.016 \\
& $\mathrm{R}^{2}$ & 0.999 & 0.998 \\
& $\varepsilon$ & 0.960 & 1.673 \\
\multirow{2}{*}{ Regression } & RMSE & 0.040 & 0.023 \\
& $\mathrm{R}^{2}$ & 0.992 & 0.997 \\
\hline
\end{tabular}

The correlations between the predicted (ANN and regression) values and actual values for draft force and disturbed soil area are shown in Figure 5 and 6 . As the correlation coefficients approach 1 , the prediction accuracy increases. In the case presented in this study, the
ANN was acquired. The relationship between depth and draft force had a curved shape and was described by means of an exponential function. An artificial neural network (ANN) model, with a back propagation learning algorithm was developed to predict draft requirements of two winged share tillage tools by Akbarnia et al., (2014). The developed model predicted the draft requirements with a mean relative error of 0.56 and mean square errors of 0.049 , when compared to measured draft force values.

For disturbed soil area, the statistical values RMSE and $\mathrm{R}^{2}$ in ANN model were found as 0.016 and 0.998 , respectively. In ANN model, the mean relative error values were found as $1.673 \%$. The statistical values RMSE and $\mathrm{R}^{2}$ in regression model were found as 0.023 and 0.997 , respectively. In regression model, the mean relative error values were found as $2.802 \%$.

Table 1 shows that $\mathrm{R}^{2}$ was very close to 1 for the ANN model. The ANN model gave smaller RMS values compared to the regression model. The ANN model gave the worst results compared to the other model. correlation coefficients obtained are very close to 1 , indicating a perfect match between the ANN predicted values and the actual values.

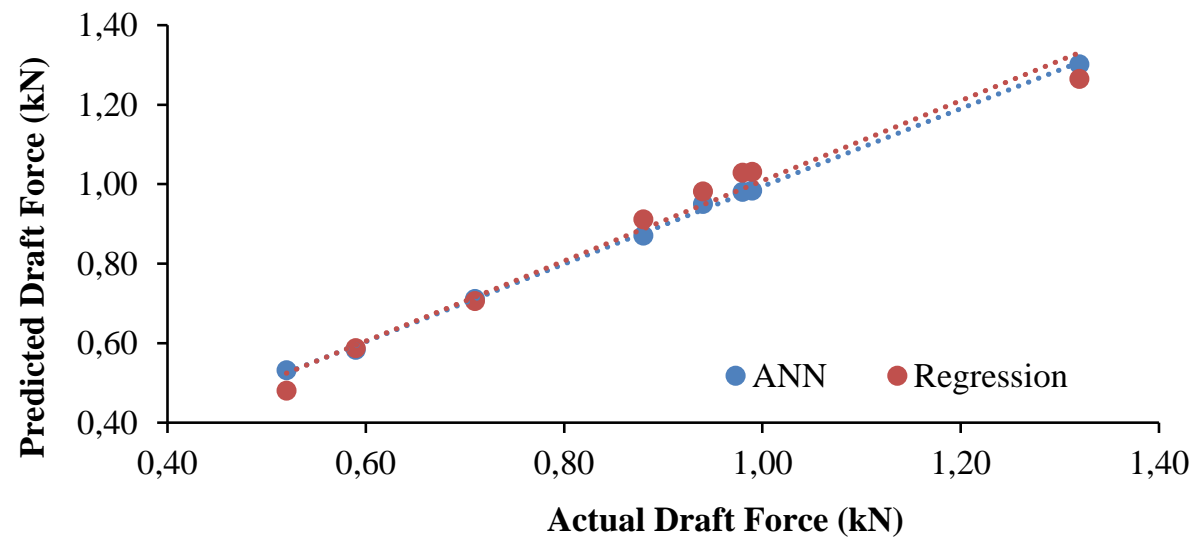

Figure 5

Correlation between predicted and actual values of draft force 


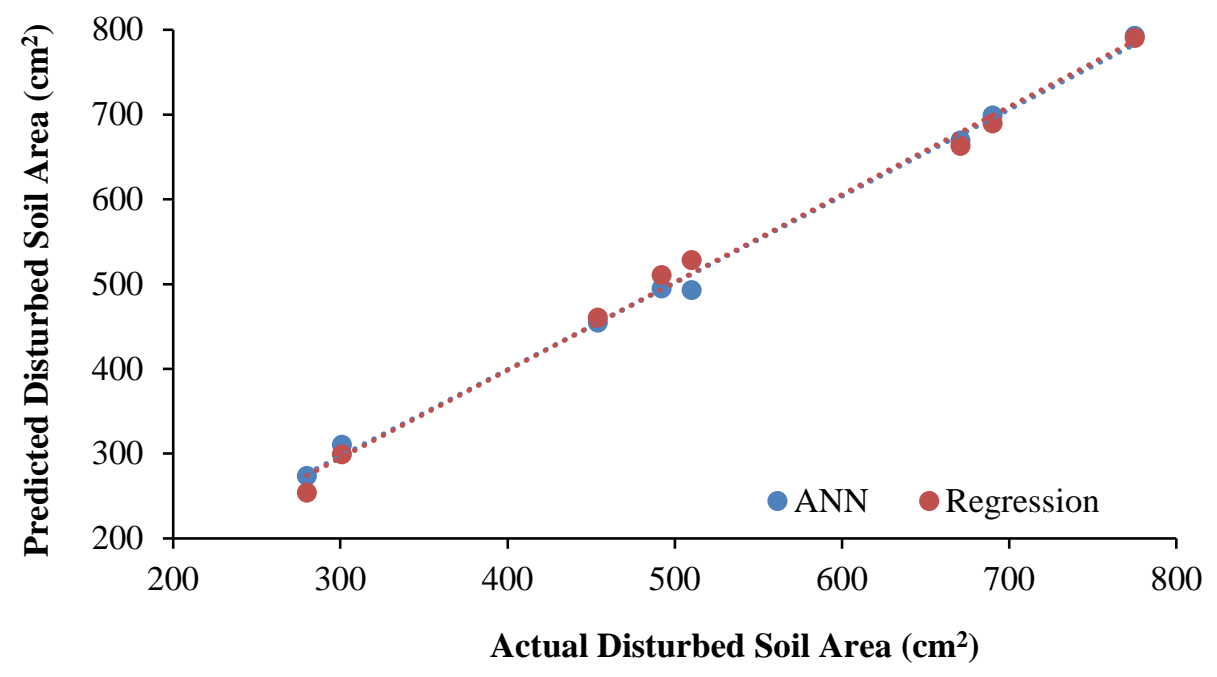

Figure 6

Correlation between predicted and actual values of disturbed soil area.

As can be seen in the figures and tables, the estimation results and the actual results are in good agreement. The deviations between predicted and actual results are very small and negligible for any draft force and disturbed soil area. These results show that the best results have been obtained with the ANN model.

\section{Conclusions}

The experiments to estimate the draft force of the chisel tine and the disturbed soil area were carried out in the soil bin under different working conditions. In the ANN model, Feed Forward Back Propagation, Multilayer Perceptron network structure the multilayer recurrent backpropagation artificial neural networks were used to predict the draft force and disturbed soil area of the chisel tine. The structure of the ANN model developed was designed to have 3 inputs, 2 hidden and 2 output layers. The input parameters of the ANNs were sharing width, forward speed and working depth. The draft force and disturbed soil area of the chisel tine were the output parameter of the designed network. To train the network, the training algorithm used was the Levenberg-Marquart algorithm. In the ANN model, $\mathrm{R}^{2}, \mathrm{RMSE}$ and relative error were found to be $0.999,0.01061$ and $0.96 \%$ for draft force and $0.998,0.01683$ and $1.67 \%$ for disturbed soil area, respectively. In the multiple linear regression model (MLR), $\mathrm{R}^{2}$, RMSE and relative error were found to be $0.992,0.04097$ and $3.75 \%$ for draft force and $0.997,0.02399$ and $2.80 \%$ for disturbed soil area, respectively. Therefore, the model developed in this paper is useful for predicting the draft force and disturbed soil area of a chisel tine and designing a chisel tine with low draft force and high disturbed soil area. It is proposed that experiments be undertaken at several soil textures, the different soil conditions and chisel tine geometries order to develop a model with high accuracy and high generalizability. In addition, this system can be compared with other artificial intelligence methods such as Fuzzy Inference System and Adaptive Neuro-Fuzzy Inference System method to get the best method to simulate the soil-chisel tine interaction under different working and soil conditions.

\section{References}

Abbaspour-Gilandeh Y, Alimardani R, Khalilian A, Keyhani AR, Sadati SH (2008). The prediction of draft force and energy required for subsoiling operation using artificial neural network model. Fifth national conference of agricultural machinery and mechanization Engineering, Iran

Abbaspour-Gilandeh Y, Fazeli M, Roshanianfard A, Hernández-Hernández M, Gallardo-Bernal I, Hernández-Hernández JL (2020). Prediction of Draft Force of a Chisel Cultivator Using Artificial Neural Networks and Its Comparison with Regression Model. Agronomy, 10,451, 1-15.

Aboukarima AWM (2007). Draft models of chisel plow based on simulation using artıficial neural networks. Farm Machinery and Power, 24(1): 42-61.

Al-Janobi AA, Aboukatima AM, Ahmed KA (2001). Prediction of Specific Draft of Different Tillage Implements Using Neural Networks. Misr Journal of Agricultural Engineering, 18 (3): 699-714.

Al-Suhaibani SA, Ghaly AE (2013). Comparative Study of the Kinetic Parameters of Three Chisel Plows Operating at Different Depths and Forward Speed in A Sandy Soil. The International Journal of Engineering and Science, 2(7), 42-59.

Akbarnia A, Mohammadi A, Farhani F, Alimardani R (2014). Simulation of draft force of winged share tillage tool using artificial neural network model. 
Agricultural Engineering International: the CIGR Journal, 16(4), 57-65.

Anderson G (2009). The impact of tillage practices and crop residue (stubble) retention in the cropping system of Western Australia. Bulletin Number 4786, ISSN: 1833-7236.

Armin A (2014). Mechanics of soil-blade interaction. PhD Thesis, Department of Mechanical Engineering University of Saskatchewan, Saskatoon.

Askari M, Shahgholi GH, Abbaspour-Gilandeh Y (2017). The effect of tine, wing, operating depth and speed on the draft force of subsoil tillage tines. Prog. Agric. Eng.Sci. 63, 160

Askari M, Abbaspour-Gilandeh Y (2019). Assessment of adaptive neuro-fuzzy inference system and response surfacemethodology approaches in draft force prediction of subsoiling tines. Soil and Tillage Research, 194, 1-8.

Bağırkan Ş (1993). İstatistiksel Analiz. Bilim Teknik Yayınevi. s. 301. İstanbul.

Bechtler H, Browne MW, Bansal PK, Kecman V (2001). New approach to dynamic modelling of vapour-compression liquid chillers: artificial neural networks. Appl Therm Eng, 21, 941-53.

Boydas MG (2004). Effect of different structural properties of some primary soil tillage implements used in wheat production on soll physical properties, field capacity, drawbar power and fuel consumption. $\mathrm{PhD}$ Thesis, Department of Agricultural Machinery, University of Atatürk, Erzurum (In Turkish).

Boydas MG (2017). Determination of effect of different wing mouth forms, different travelling speeds and different working depths on draft force in wings used in winged chisel plough. Mediterranean Agricultural Sc1ences, 30(3), 219-225 (In Turkish)

Çarman K, Marakoglu T, Taner A, Mikailsoy F (2016). Measurements and modelling of wind erosion rate in different tillage practices using a portable wind erosion tunnel. Zemdirbyste-Agriculture, 103 (3), 327334.

Çarman K, Çıtıl E, Taner A (2019). Artificial Neural Network Model for Predicting Specific Draft Force and Fuel Consumption Requirement of a Mouldboard Plough. Selcuk Journal of Agriculture and Food Sciences, 33 (3), 241-247.

Fawcett R, Towery D (2005). Conservation Tillage and Plant Biotechnology: How New Technologies Can Improve the Environment By Reducing the Need to Plow. Conservation Technology Information Center, West Lafayette, USA.

Godwin R J, O’Dogherty MJ (2007). Integrated soil tillage force prediction models. Journal of Terramechanics, 44, 3-14.

Karmakar S (2005). Numerical modelling of soil flow and pressure distribution on a simple tillage tool us- ing computational fluid dynamics. PhD Thesis, Department of Agricultural and Bioresource Engineering, University of Saskatchewan, Canada.

Kees G (2008). Using subsoiling to reduce soil compaction. USDA Forest Service Technology and Development Program Missoula, MT. http://www.fs.fed.us/t/pubs/pdfpubs/pdf08342828/ pdf08342828dpi72.pdf.

Manuwa SI (2009). Performance evaluation of tillage tines operating under different depths in a sandy clay loam soil. Soil and Tillage Research, 103, 399-405.

Manuwa SI, Ademosun OC, Agbetoye LAS, Adesina A (2010). Soil bin investigations of the effects of tillage tool width on draught and soil disturbance parameters in sandy clay loam soil. XVII. World Congress of the International Commission of Agricultural and Biosystems Engineering (CIGR), 1-9.

Marakoğlu T, Çarman K, Çitil E (2013). The effect on soil deformation of different type chisel share. Journal of Agricultural Machinery Science, 9(3), 175179 (In Turkish).

Neisy I (2014). Introduction to the study of soil-tool modelling. Walia journal, 30(1), 31-34.

Purushothaman S, Srinivasa YG (1994). A back-propagation algorithm applied to tool wear monitor-ing. International Journal of Machine Tools and Manufacture, 34(5): 625-631.

Rahman A, Kushawaha RL, Ashrafizadeh SR, Panigrahi S (2011). Prediction of energy requirement of a tillage tool in a soil bin using artificial neural network. ASABE Paper No. 111112. USA.

Salar MR, Esehaghbeygi A, Hemmat A (2013). Soil loosening characteristics of a dual bent blade subsurface tillage implement. Soil and Tillage Research 134:17-24.

Simmons FW, Nafziger ED (2010). Soil Management and Tillage. Illinois Agronomy Handbook, pp.133142.

Scott BJ, Eberbach PL, Evans J, Wade LJ (2010). Stubble retention in cropping systems in Southern Australia: Benefits and Challenges. Industry and Investment NSW, ISBN: 9781742560205.

Suzuki K (2013). Artificial Neural Networks: Architectures and Applications; InTech Publisher: Rijeka, Croatia.

Topakc1 M (2004). A study on the improvement of soil failure area in tillage by chisel tine. PhD Thesis, Department of Agricultural Machinery, University of Akdeniz, Antalya (In Turkish).

Zadeh SRA (2006). Modelling of energy requirements by A narrow tillage tool. PhD Thesis, Department of Agricultural and Bioresource Engineering University of Saskatchewan, Saskatoon. 